\title{
Does psychosocial support buffer the effect of COVID-19 related stressors on mental health among Chinese during quarantine?
}

\author{
Ying Wang ${ }^{1}$ (D) Tolulope Ariyo $^{1} \cdot$ Huijun Liu ${ }^{1} \cdot$ Chenjuan $\mathrm{Ma}^{2}$ \\ Accepted: 19 March 2021 / Published online: 27 May 2021 \\ (C) The Author(s), under exclusive licence to Springer Science+Business Media, LLC, part of Springer Nature 2021
}

\begin{abstract}
The effect of the COVID-19 related stressors on the mental health of both infected patients and the general public has been well established. However, knowledge is limited on how psychosocial support buffers the association. This study aimed to examine this buffering role in the context of China. We utilized cross-sectional data collected online in mid-March 2020, involving 585 respondents. Mental health status was determined through depression symptoms and loneliness. COVID-19 related stressors include three aspects: perceived severity, perceived threat to life and health, and perceived risk of COVID-19 infection. Psychosocial support included family and social supports. Analyses include ordinary linear regression. The finding showed that psychosocial support buffered the negative effect of loneliness in the context of perceived severity of COVID-19, but appeared to intensify the negative effect of depression symptoms in the context of perceived threat to life and health. However, there was no significant buffering effect on depression or loneliness in the context of the perceived risk of infection. The buffering effect of psychosocial support on COVID-19 related stressors is of mixed patterns. This study contributes to the emerging body of literature trying to understand how the COVID-19 impacts the mental health of individuals.
\end{abstract}

Keywords Coronavirus $2 \cdot$ Loneliness $\cdot$ Depression $\cdot$ Anxiety symptoms $\cdot$ Social support

\section{Introduction}

The coronavirus disease (COVID-19, also known as 2019$\mathrm{nCoV}$ ) is an infectious disease first reported of human transmission in late 2019 (World Health Organization, 2020b). Few months following the outbreak, the number of reported cases increased exponentially across nations, which led the World Health Organization (WHO) to declare it a pandemic. As of December 2020, about a year since the index case, there have been more than 70 million infections globally, with more than 1.6 million fatalities (Johns Hopkins University and Medicine, 2020).

A pandemic can induce high levels of psychological stress arising from fear of infection of a fatal disease that has no

Chenjuan Ma

cm4215@nyu.edu

Ying Wang

18209284606@163.com

1 Institute for Population and Development Studies, School of Public Policy and Administration, Xi' an Jiaotong University, Xi' an 710049, China

2 New York University Rory Meyers College of Nursing, 433 First Ave, New York, NY 10010, USA known therapeutic. Without a vaccine and with a continued surge in cases of COVID-19 infection nationally and internationally, social distancing (among other measures) was a strategy recommended by epidemiologists and policymakers for reducing and preventing further transmissions (World Health Organization, 2020a). Nationwide, the Chinese government adopted strict top-down epidemic prevention and control measures including, lockdown, shelter-in-place, quarantine, social distancing, restrictions on commuting and traveling, and public events. For example, Wuhan, the first epicenter of the COVID-19 pandemic, was the first city with a lockdown order, which lasted for 76 days. In many other cities and provinces where the COVID-19 situation was less severe, government regulations varied from shelter-in-place to restrictions on commuting and traveling. These interventions, necessary as they were, could have impacted an individual's mental health, as daily activities and social interaction were greatly impacted (Ahmed et al., 2020; Brooks et al., 2020; Pandey et al., 2020; Sharma et al., 2020).

The relationship between the COVID-19 outbreak and mental health has a depiction in the Stress Process Model as espoused by Pearlin et al., (1981). This model posits that strenuous life events may impact mental health. The COVID-19 outbreak depicts a strenuous life event in the sense that it posed a challenge to people's psychological endurance. 
More importantly, the Stress Process Model proposes a buffering hypothesis (Cohen \& Wills, 1985), and suggests that psychosocial support has the potency to mitigate against the manifestation of stress in the context of stressors from strenuous life events (Pearlin et al., 1981). Therefore, as suggested by this Stress Process Model, individuals who were able to leverage useful psychosocial support in the context of negative psychological consequences of the lockdown measures, are likely to have a mitigated psychological outcome.

In the past several months since the COVID-19 pandemic, several studies have reported the impact of COVID-19 related stressors on poor mental health including anxiety, depression, delirium, loneliness, etc., among both infected patients and the general public (Holmes et al., 2020; Huang \& Zhao, 2020; Lin et al., 2020; Rogers et al., 2020; Salari et al., 2020). While such knowledge is important for a full understanding of the impact of COVID-19 beyond physical harms due to infection, little is known of factors or resources that could mitigate the negative impact on mental health. To date, only a few studies have investigated the role of psychosocial support in buffering the influence of COVID-19 related stressors on mental health. Psychosocial support refers to the support given to meet mental, emotional, social, and spiritual needs in times of distress (National Cancer Institute, n.d.). It may generally be obtained from relatives or people in one's social network (Turner \& Brown, 2010).

In two studies, the researchers examined the role of psychosocial support in the relationship between COVID-19 related stressors and mental health (Duan et al., 2020; Ye et al., 2020). Although while both studies were done in the context of China, Ye et al., (2020) was focused on the outcome of acute stress disorder, while the Duan et al., (2020) on the other hand examined the buffering effect of psychosocial support in how COVID19 stressor affected hostility, -a form of behavioral change. Therefore, knowledge is still limited about how psychosocial support buffers the effect of COVID-19 related stressors on mental health among the general population in China.

Providing knowledge in this regard will be of importance for mental health practitioners equipping them with the understanding of what or how psychosocial support is important in mitigating the effect of COVID-19 stressors. Therefore, this study aims to 1) examine how COVID-19 stressors affect depression and loneliness among the general population, and 2) identify the extent to which psychosocial resources, including family and social support, buffers the effect of COVID-19 related stressors on mental health among the general population.

\section{Method}

\section{Research Design, Data, and Sample}

This study used a cross-sectional design. Data were collected anonymously online via the Wen Juan Xing survey platform (https://www.wjx.cn/) from March 10 to 17. Information collected from participants included social-demographics, socio-economic status, perception about COVID-19 as a stressor, perceived mental health status, and psychosocial resources. The research protocol was reviewed and approved by the Biomedical Ethics Committee of the lead author's institution.

We used the snowball sampling technique to recruit participants. The distribution of online link to the questionnaire at the Juan Xing survey platform was initiated by members of the research team using WeChat and QQ - the two most popular social media platforms in China (1.2 billion and 0.7 billion monthly active users, respectively, as of Q4 in 2019). The research team members were from different regions of China, which helped increase the geographic diversity of our participants. All participants were informed that participation was voluntary and anonymous, and consent was implied if the participant proceeded with completing the questionnaire. Participants were asked to share the questionnaire link with their contacts after completing the survey. Eligibility for participation included residence in mainland China since the start of COVID-19 pandemic, being at least 16 years old, and having access to a smartphone or computer to complete the survey. After deleting three respondents younger than 16 years that accidentally completed the survey, the final sample used for analysis was 585 .

\section{Measures}

\section{Depression Symptom}

Depression symptom is one of the two outcome variables. It was measured using a short version of the Center for Epidemiologic Studies Depression Scale which included 10 items (CES-D-10) (Andresen et al., 1994). The CES-D-10 has good psychometric properties (Dershem et al., 1996), and has been validated for use among Chinese ( $\mathrm{S}$. T. Cheng \& Chan, 2005). It includes questions on how often the respondent has felt and behaved in a specific scenario during last week. Each item was rated on a four-point Likert scale, ranging from 1 to 4 ( $1=$ rarely or none of the time, $<1$ day; $2=$ Some or a little of the time, $1-2$ days; $3=$ Occasionally or a moderate amount of the time, 3-4 days; $4=$ Most or all of the time, 5-7 days). Scoring was reversed for items 5 and 8 , which were two positive items. A summary score was calculated as the sum of the scores from the 10 items. The summary score ranged from 10 to 40 , with higher scores indicating greater depressive symptoms. The reliability coefficient was $\alpha=0.84$ in this study.

\section{Loneliness}

The other outcome variable was loneliness. It was measured using the UCLA 3-item Loneliness Scale (Hughes et al., 
2004), which has also been used in research from China (Dong et al., 2007; Sweeny et al., 2020). Items on the scale are rated on a three-point Likert scale, ranging from 1 to 3 for each item $(1=$ hardly ever, $2=$ some of the time, $3=$ often $)$. A total score of the three items was calculated to indicate the level of loneliness with higher scores indicating greater loneliness. Loneliness scores ranged from 3 to 9 . The reliability coefficient was $\alpha=0.85$.

\section{COVID-19 Related Stressors}

The main dependent variables were COVID-19 related stressors. Based on Lin et al., (2020), we measured it as participants' perceptions about COVID-19 from three aspects: (1) perceived severity of COVID-19; (2) perceived COVID19 threat to life and health, and (3) perceived risk of COVID19 infection.

Perceived severity of COVID-19 was measured by asking participants "Overall, how severe do you consider COVID19?" Response options run on a scale of not at all, to very much. Based on the distribution of answers, participants were categorized into two groups $(1=$ severe/very severe and $0=$ not at all/slightly/fairly) due to an extremely small proportion of participants that selected "not at all". Perceived COVID-19 threat to life and health was measured by asking participants "How much do you feel that COVID-19 pandemic threatens your life and health?" Participants were assigned into three groups, those answering not at all/slightly (coded 0), those answering moderate (coded 1), and those answering threatening/very threatening (coded 2). Perceived risk of COVID-19 infection was measured by asking participants "How likely do you think you will be infected with COVID19?" Participants were also categorized into three groups based on their answers, definitely not/probably not (0), fairly (1), probably/definitely (2).

\section{Psychosocial Support}

Psychosocial support during the COVID-19 pandemic was measured using the Chinese Family Support Scale (CFSS) (Li et al., 2013). The original CFSS consists of three subscales, namely kinship support (parents and relatives), nuclear family support (spouse and children), and social support (community organization, professional agencies, friends, and co-workers/neighbors). In this study, we considered parents as part of the family support source instead of kinship support. This was because the COVID-19 crisis happened around the Lunar New Year holiday which is a traditional holiday known for family reunions. Given the extended holiday time and orders of shelter-in-place or lockdown based on where the participants were, most people are likely to be with parents. Also, in the Chinese culture, parents are often considered part of the nuclear family, and it is not uncommon for parents and their adult children to live together in the same house in general (Chou, 2011).

Therefore, we measured psychosocial support from two perspectives, family support, and social support. The former included support from parents, spouse, and children during COVID-19 pandemic (3 items). The latter included support from relatives, friends, co-workers/classmates, community organizations/the village committee, professional agencies, and other social organization during COVID-19 pandemic (6 items). Each item was rated on a 6-point Likert scale, ranging from "not available" (0) to "extremely helpful" (5). Item scores were summed for each type of support, which resulted in family support scores ranging from 3 to 18 and social support scores from 6 to 36 . The reliability coefficient was $\alpha=$ 0.66 for family support and $\alpha=0.90$ for social support. For both measures, higher scores indicated better support.

\section{Covariates}

A set of socio-demographic variables that might influence the outcome measure and/or confound the relationship between our dependent and independent variables were included in analyses. These variables include age (in years), gender, education (below college vs. college and above), marital status (currently married vs. not currently married), and annual income ( $<30,000$ vs. $>=30,000$ RMB). Furthermore, self-rated health $(\mathrm{SRH})$ was also included $(1=$ very poor, $2=$ poor, $3=$ fair, $4=$ good, $5=$ very good) as a covariate.

\section{Statistical Analysis}

Analyses were performed using Stata version 15.0 (StataCorp LP). Descriptive statistics, which included mean and standard deviation (SD) for continuous variables, and frequency and percentage for categorical variables were used to summarize the distribution of variables. A series of multivariate regression models were used to examine the impact of COVID-19 related stressors on the outcome variables (i.e., depressive symptoms and loneliness) and the buffering effect of psychosocial support variables on the association between COVID19 stressors and outcomes. All models were adjusted for socio-demographic characteristics and SRH.

We first included a single measure of COVID-19 related stressors and the covariates in the model (Model 1). We then added psychosocial variables (family and social support) (Model 2). Finally, we explored the potential moderating effects of psychosocial support by adding an interaction term between each measure of COVID-19 related stressor and family support (Model 3) or social support (Model 4). To compensate for the low power associated with multiplicative variables, we used $p<0.10$ to identify statistically significant effects for interactions. 


\section{Results}

\section{Sample Characteristics and Univariate Analysis}

Participants in the study were from 29 out of the 32 provinces, municipalities, and regions in mainland China, including 9 (or $1.53 \%$ ) individuals from Hubei Province of which Wuhan is the capital city. About $92.14 \%(n=539)$ of the participants lived with their families, only $4.10 \%(n=24)$ lived alone, and $3.76 \%(n=22)$ lived with others during the quarantine. Other characteristics of the study participants are shown in Table 1. For the 585 respondents, their age ranged from 16 to 59 years with a mean age of 29.63 years $(\mathrm{SD}=8.54)$. Two in five $(40.51 \%)$ reported being currently married. The majority of the respondents were females $(63.6 \%)$, nearly $90 \%$ had at least a college education, and about $54.0 \%$ earn an annual income of thirty thousand $(30,000) \mathrm{RMB}$ or more. The respondents generally perceived themselves to be in good health, implied by an average SRH score of $4.5(\mathrm{SD}=0.70)$, in a range between 1 and 5 .

Table 1 Descriptive statistics $(N=585)$

\begin{tabular}{|c|c|c|c|c|}
\hline Variables & Mean & $\mathrm{SD}$ & $\mathrm{N}$ & $\%$ \\
\hline \multicolumn{5}{|l|}{ Mental health outcomes } \\
\hline Depression symptoms & 17.99 & 5.32 & & \\
\hline Loneliness & 4.21 & 1.43 & & \\
\hline \multicolumn{5}{|l|}{ Sociodemographic characteristics } \\
\hline Age & 29.63 & 8.54 & & \\
\hline Female & & & 372 & 63.59 \\
\hline College and above & & & 524 & 89.57 \\
\hline Currently married & & & 237 & 40.51 \\
\hline \multicolumn{5}{|l|}{ Annual income } \\
\hline \multicolumn{5}{|l|}{$<30,000 \mathrm{RMB}$} \\
\hline$>=30,000 \mathrm{RMB}$ & & & 316 & 54.02 \\
\hline Self-rated health & 4.54 & 0.70 & & \\
\hline \multicolumn{5}{|l|}{ COVID-19 related stressors } \\
\hline Perceived severity & & & 505 & 86.32 \\
\hline \multicolumn{5}{|c|}{ Perceived threat to life and health } \\
\hline Not at all/slightly threat & & & 223 & 38.12 \\
\hline Moderate & & & 179 & 30.60 \\
\hline Severe & & & 183 & 31.28 \\
\hline \multicolumn{5}{|l|}{ Perceived risk of infection } \\
\hline Definitely not/probably not & & & 293 & 50.09 \\
\hline Fair & & & 215 & 36.75 \\
\hline Probably/definitely & & & 77 & 13.16 \\
\hline \multicolumn{5}{|l|}{ Psychosocial resources } \\
\hline Family support & 11.95 & 4.37 & & \\
\hline Social support & 25.36 & 7.55 & & \\
\hline
\end{tabular}

On average, respondents had a depression symptom score of $18.0(\mathrm{SD}=5.32)$, and a loneliness score of $4.2(\mathrm{SD}=1.43)$. The majority, representing $86.3 \%$ perceived COVID-19 to be severe, and about $61.9 \%$ of the respondents perceived COVID-19 as moderately or severely threatening to life and health. Approximately, half of the respondents $(50.1 \%)$ reported perceiving themselves as being at no risk of COVID19 infection, while $13.3 \%$ had the perception of probably/ definitely being at risk of infection. The family and social support scores among the respondents were $11.9(\mathrm{SD}=$ $4.37)$, and $25.4(\mathrm{SD}=7.55)$, respectively.

\section{Multivariate Analysis}

\section{Perceived Severity of COVID-19, Psychosocial Support, Depression, and Loneliness}

Table 2 shows the result from the multivariate regression analysis on how the perceived severity of COVID-19 was associated with depression symptoms and loneliness. In model 1, the coefficients indicated that the perceived severity of COVID19 was not associated with both depression symptoms and loneliness after adjusting for covariates. After adding psychosocial resource variables (family and social support) (Model $2)$, an association between family support and depression was observed $(\beta=-0.12 ; p<0.01)$.

Next, the effect of an interaction between the perceived severity of COVID-19 and family support on depression and loneliness were examined in model 3 . The result indicated that this interaction was not significant on depression, but significant on loneliness $(\beta=-0.08 ; p<0.05)$. Furthermore, the effect of an interaction between the perceived severity of COVID-19 and social support on depression symptoms and loneliness were examined in model 4. While this interaction was not significant for depressive symptoms, it was significant for loneliness, but only $\operatorname{marginally}(\beta=-0.04 ; p<0.1)$.

\section{The Perceived Threat of COVID-19 to Life and Health, Psychosocial Support, Depression, and Loneliness}

Table 3 shows the result from the multivariate regression analysis on the perception of COVID-19 as a threat to life and health, and its association with depression and loneliness. In model 1 , compared to those who did not perceive COVID-19 as a threat to life and health, respondents perceiving it as a threat were more likely to have higher depression symptoms (moderate group: $\beta=1.10$; $p<0.05$; severe group: $(\beta=1.58 ; p<0.05)$. This effect barely attenuated in subsequent models. On the other hand, the perceived threat of COVID-19 to life and health was not associated with loneliness. In model 2 , both the family and social support variables were added, and a 
Table 2 The buffering role of psychosocial supports in the association between perceived severity of the COVID-19, depression symptoms and loneliness

\begin{tabular}{|c|c|c|c|c|c|c|c|c|}
\hline & \multicolumn{4}{|c|}{ Depression } & \multicolumn{4}{|c|}{ Loneliness } \\
\hline & $\begin{array}{l}\text { Model } 1 \\
\beta(\mathrm{SE})\end{array}$ & $\begin{array}{l}\text { Model } 2 \\
\beta(\mathrm{SE})\end{array}$ & $\begin{array}{l}\text { Model } 3 \\
\beta(\mathrm{SE})\end{array}$ & $\begin{array}{l}\text { Model } 4 \\
\beta(\mathrm{SE})\end{array}$ & $\begin{array}{l}\text { Model } 1 \\
\beta(\mathrm{SE})\end{array}$ & $\begin{array}{l}\text { Model } 2 \\
\beta(\mathrm{SE})\end{array}$ & $\begin{array}{l}\text { Model } 3 \\
\beta(\mathrm{SE})\end{array}$ & $\begin{array}{l}\text { Model } 4 \\
\beta(\mathrm{SE})\end{array}$ \\
\hline \multirow[t]{2}{*}{ Age } & -0.03 & -0.03 & -0.03 & -0.03 & -0.01 & -0.01 & -0.01 & -0.01 \\
\hline & $(0.04)$ & $(0.04)$ & $(0.04)$ & $(0.04)$ & $(0.01)$ & $(0.01)$ & $(0.01)$ & $(0.01)$ \\
\hline \multirow[t]{2}{*}{ Gender ( 1 = female $)$} & 0.83 & $0.93^{*}$ & $0.92 *$ & $0.93 *$ & 0.15 & 0.17 & 0.16 & 0.17 \\
\hline & $(0.44)$ & $(0.44)$ & $(0.44)$ & $(0.44)$ & $(0.12)$ & $(0.12)$ & $(0.12)$ & $(0.12)$ \\
\hline \multirow[t]{2}{*}{ Education ( 1 = college and above) } & -0.26 & -0.37 & -0.36 & -0.38 & -0.06 & -0.08 & -0.05 & -0.05 \\
\hline & $(0.78)$ & $(0.78)$ & $(0.78)$ & $(0.78)$ & $(0.21)$ & $(0.22)$ & $(0.22)$ & $(0.22)$ \\
\hline \multirow[t]{2}{*}{ Marital status ( 1 = currently married) } & $-1.70^{*}$ & $-1.91 * *$ & $-1.92 * *$ & $-1.91 * *$ & -0.12 & -0.17 & -0.17 & -0.18 \\
\hline & $(0.68)$ & $(0.71)$ & $(0.72)$ & $(0.72)$ & $(0.19)$ & $(0.20)$ & $(0.20)$ & $(0.20)$ \\
\hline \multirow[t]{2}{*}{ Annual income ( $1=“>=30,000$ RMB”) } & -0.71 & -0.69 & -0.69 & -0.69 & -0.17 & -0.17 & -0.17 & -0.17 \\
\hline & $(0.51)$ & $(0.51)$ & $(0.51)$ & $(0.51)$ & $(0.14)$ & $(0.14)$ & $(0.14)$ & $(0.14)$ \\
\hline \multirow[t]{2}{*}{ Self-rated health } & $-1.39 * * *$ & $-1.27 * * *$ & $-1.27 * * *$ & $-1.27 * * *$ & -0.13 & -0.10 & -0.10 & -0.11 \\
\hline & $(0.30)$ & $(0.31)$ & $(0.31)$ & $(0.31)$ & $(0.08)$ & $(0.08)$ & $(0.08)$ & $(0.08)$ \\
\hline \multicolumn{9}{|l|}{ COVID-19 related stressor } \\
\hline \multirow[t]{2}{*}{ Perceived severity } & 0.15 & 0.13 & 0.13 & 0.13 & 0.19 & 0.18 & 0.18 & 0.18 \\
\hline & $(0.61)$ & $(0.61)$ & $(0.61)$ & $(0.61)$ & $(0.17)$ & $(0.17)$ & $(0.17)$ & $(0.17)$ \\
\hline \multicolumn{9}{|l|}{ Psychosocial resources } \\
\hline \multirow[t]{2}{*}{ Family support } & & 0.09 & 0.13 & 0.09 & & 0.02 & $0.09 *$ & 0.02 \\
\hline & & $(0.07)$ & $(0.13)$ & $(0.07)$ & & $(0.02)$ & $(0.04)$ & $(0.02)$ \\
\hline \multirow[t]{2}{*}{ Social support $\$$} & & $-0.12 * *$ & $-0.12 * *$ & $-0.13+$ & & $-0.02+$ & $-0.02 *$ & 0.02 \\
\hline & & $(0.04)$ & $(0.04)$ & $(0.08)$ & & $(0.01)$ & $(0.01)$ & $(0.02)$ \\
\hline \multicolumn{9}{|l|}{ Interaction terms } \\
\hline \multirow[t]{2}{*}{ Perceived severity of the COVID- $19 \times$ family support } & & & -0.04 & & & & $-0.08^{*}$ & \\
\hline & & & $(0.13)$ & & & & $(0.04)$ & \\
\hline \multirow[t]{2}{*}{ Perceived severity of the COVID-19× social support } & & & & 0.01 & & & & $-0.04+$ \\
\hline & & & & $(0.08)$ & & & & $(0.02)$ \\
\hline Adjusted $\mathrm{R}^{2}$ & 0.076 & 0.088 & 0.087 & 0.087 & 0.003 & 0.005 & 0.012 & 0.009 \\
\hline
\end{tabular}

$\mathrm{S} E$ Standard Error

\$Variables are mean centered

significant negative association was observed for the relationship between social support and depression $(\beta=-$ $0.12 ; p<0.01)$.

The effect of an interaction between the perceived threat of COVID-19 to life and health and family support on depression symptoms and loneliness was examined in model 3. The interaction effect was only significant for depression. The result reveals that perceived severe threat of COVID-19 to life and health significantly interacts with family support $(\beta=0.36 ; p<0.01)$. Furthermore, we tested the interaction of the perceived severity of COVID19 to life and health and social support on depression symptoms and loneliness in model 4 . It showed that the effect of the interaction was also only significant for depression. The result suggests that perceived severe threat of COVID-19 to life and health significantly interacts with social support $(\beta=0.14 ; p<0.05)$.

\section{Perceived Risk of COVID-19 Infection, Psychosocial Support, Depression, and Loneliness}

Table 4 shows the result from the multivariate regression analysis on the perceived risk of COVID-19 infection and its association with depression and loneliness. As shown in model 1 , compared to those who had the perception that they were not at risk of COVID-19 infection, those who hold the perception that they were certainly or almost certainly at risk of infection were significantly more likely of having a higher depression score $(\beta=2.32 ; p<0.001)$, as well as higher loneliness score $(\beta=0.26 ; p<0.05)$. 
Table 3 The buffering role of psychosocial supports in the association between perceived COVID-19 threat, depression symptoms and loneliness

\begin{tabular}{|c|c|c|c|c|c|c|c|c|}
\hline & \multicolumn{4}{|c|}{ Depression } & \multicolumn{4}{|c|}{ Loneliness } \\
\hline & $\begin{array}{l}\text { Model } 1 \\
\beta(\mathrm{SE})\end{array}$ & $\begin{array}{l}\text { Model } 2 \\
\beta(\mathrm{SE})\end{array}$ & $\begin{array}{l}\text { Model } 3 \\
\beta(\mathrm{SE})\end{array}$ & $\begin{array}{l}\text { Model } 4 \\
\beta(\mathrm{SE})\end{array}$ & $\begin{array}{l}\text { Model } \\
1 \\
\beta(\mathrm{SE})\end{array}$ & $\begin{array}{l}\text { Model } \\
2 \\
\beta(\mathrm{SE})\end{array}$ & $\begin{array}{l}\text { Model } \\
3 \\
\beta(\mathrm{SE})\end{array}$ & $\begin{array}{l}\text { Model } \\
4 \\
\beta(\mathrm{SE})\end{array}$ \\
\hline Age & $\begin{array}{c}-0.03 \\
(0.04)\end{array}$ & $\begin{array}{c}-0.03 \\
(0.04)\end{array}$ & $\begin{array}{c}-0.03 \\
(0.04)\end{array}$ & $\begin{array}{c}-0.03 \\
(0.04)\end{array}$ & $\begin{array}{c}0.01 \\
(0.01)\end{array}$ & $\begin{array}{c}0.01 \\
(0.01)\end{array}$ & $\begin{array}{c}0.01 \\
(0.01)\end{array}$ & $\begin{array}{c}0.01 \\
(0.01)\end{array}$ \\
\hline Gender $(1=$ female $)$ & $\begin{array}{c}0.78 \\
(0.44)\end{array}$ & $\begin{array}{c}0.88^{*} \\
(0.44)\end{array}$ & $\begin{array}{c}0.91 * \\
(0.43)\end{array}$ & $\begin{array}{c}0.89 * \\
(0.44)\end{array}$ & $\begin{array}{c}0.16 \\
(0.12)\end{array}$ & $\begin{array}{c}0.17 \\
(0.12)\end{array}$ & $\begin{array}{c}0.17 \\
(0.12)\end{array}$ & $\begin{array}{l}017 \\
(0.12)\end{array}$ \\
\hline Education ( 1 =college and above) & $\begin{array}{c}-0.51 \\
(0.78)\end{array}$ & $\begin{array}{c}-0.62 \\
(0.77)\end{array}$ & $\begin{array}{c}-0.64 \\
(0.77)\end{array}$ & $\begin{array}{l}-0.65 \\
(0.78)\end{array}$ & $\begin{array}{c}-0.07 \\
(0.22)\end{array}$ & $\begin{array}{l}-0.09 \\
(0.22)\end{array}$ & $\begin{array}{l}-0.09 \\
(0.22)\end{array}$ & $\begin{array}{c}-0.11 \\
(0.22)\end{array}$ \\
\hline Marital status ( 1 =currently married) & $\begin{array}{c}-1.75^{* *} \\
(0.67)\end{array}$ & $\begin{array}{c}-1.96^{* *} \\
(0.71)\end{array}$ & $\begin{array}{c}-1.95^{* *} \\
(0.70)\end{array}$ & $\begin{array}{c}-1.88^{* *} \\
(0.71)\end{array}$ & $\begin{array}{c}-0.13 \\
(0.19)\end{array}$ & $\begin{array}{c}-0.18 \\
(0.20)\end{array}$ & $\begin{array}{c}-0.18 \\
(0.20)\end{array}$ & $\begin{array}{c}-0.17 \\
(0.20)\end{array}$ \\
\hline Annual income ( $1=$ ">=30,000 RMB") & $\begin{array}{l}-0.68 \\
(0.51)\end{array}$ & $\begin{array}{c}-0.66 \\
(0.51)\end{array}$ & $\begin{array}{l}-0.65 \\
(0.50)\end{array}$ & $\begin{array}{l}-0.65 \\
(0.51)\end{array}$ & $\begin{array}{c}-0.17 \\
(0.14)\end{array}$ & $\begin{array}{c}-0.16 \\
(0.14)\end{array}$ & $\begin{array}{c}-0.16 \\
(0.14)\end{array}$ & $\begin{array}{c}-0.16 \\
(0.14)\end{array}$ \\
\hline Self-rated health & $\begin{array}{c}-1.41 * * * \\
(0.30)\end{array}$ & $\begin{array}{c}-1.29 * * * \\
(0.31)\end{array}$ & $\begin{array}{c}-1.32 * * * \\
(0.31)\end{array}$ & $\begin{array}{c}-1.27 * * * \\
(0.31)\end{array}$ & $\begin{array}{c}-0.12 \\
(0.08)\end{array}$ & $\begin{array}{l}-0.10 \\
(0.09)\end{array}$ & $\begin{array}{c}-0.11 \\
(0.09)\end{array}$ & $\begin{array}{c}-0.09 \\
(0.08)\end{array}$ \\
\hline \multicolumn{9}{|l|}{ COVID-19 related stressor } \\
\hline \multicolumn{9}{|l|}{ Perceived threat to life and health ${ }^{a}$} \\
\hline Moderate & $\begin{array}{c}1.10^{*} \\
(0.51)\end{array}$ & $\begin{array}{c}1.06^{*} \\
(0.51)\end{array}$ & $\begin{array}{c}1.05^{*} \\
(0.51)\end{array}$ & $\begin{array}{c}1.05^{*} \\
(0.51)\end{array}$ & $\begin{array}{c}0.01 \\
(0.14)\end{array}$ & $\begin{array}{c}0.01 \\
(0.14)\end{array}$ & $\begin{array}{c}0.01 \\
(0.14)\end{array}$ & $\begin{array}{c}0.01 \\
(0.14)\end{array}$ \\
\hline Severe & $\begin{array}{l}1.58^{* *} \\
(0.51)\end{array}$ & $\begin{array}{l}1.59^{* *} \\
(0.50)\end{array}$ & $\begin{array}{l}1.48^{* *} \\
(0.50)\end{array}$ & $\begin{array}{l}1.56^{* *} \\
(0.51)\end{array}$ & $\begin{array}{c}0.21 \\
(0.14)\end{array}$ & $\begin{array}{c}0.21 \\
(0.14)\end{array}$ & $\begin{array}{c}0.19 \\
(0.14)\end{array}$ & $\begin{array}{c}0.20 \\
(0.14)\end{array}$ \\
\hline \multicolumn{9}{|l|}{ Psychosocial resources } \\
\hline Family support $\ddagger$ & & $\begin{array}{c}0.09 \\
(0.07)\end{array}$ & $\begin{array}{l}-0.06 \\
(0.10)\end{array}$ & $\begin{array}{c}0.09 \\
(0.07)\end{array}$ & & $\begin{array}{c}0.02 \\
(0.02)\end{array}$ & $\begin{array}{c}-0.01 \\
(0.03)\end{array}$ & $\begin{array}{c}0.02 \\
(0.02)\end{array}$ \\
\hline Social support: & & $\begin{array}{c}-0.12^{* *} \\
(0.04)\end{array}$ & $\begin{array}{c}-0.12^{* *} \\
(0.04)\end{array}$ & $\begin{array}{l}-0.18 * * * \\
(0.05)\end{array}$ & & $\begin{array}{c}-0.02+ \\
(0.01)\end{array}$ & $\begin{array}{c}-0.02+ \\
(0.01)\end{array}$ & $\begin{array}{c}-0.03 * \\
(0.01)\end{array}$ \\
\hline \multicolumn{9}{|l|}{ Interaction terms } \\
\hline $\begin{array}{l}\text { Perceived COVID-19 threat to life and health (moderate) } \times \\
\text { family support }\end{array}$ & & & $\begin{array}{c}0.12 \\
(0.12)\end{array}$ & & & & $\begin{array}{c}0.03 \\
(0.03)\end{array}$ & \\
\hline $\begin{array}{l}\text { Perceived COVID-19 threat to life and health (severe) } \times \text { family } \\
\text { support }\end{array}$ & & & $\begin{array}{l}0.36^{* *} \\
(0.12)\end{array}$ & & & & $\begin{array}{c}0.05 \\
(0.03)\end{array}$ & \\
\hline $\begin{array}{l}\text { Perceived COVID-19 threat to life and health (moderate) } \times \text { social } \\
\text { support }\end{array}$ & & & & $\begin{array}{c}0.05 \\
(0.07)\end{array}$ & & & & $\begin{array}{c}0.02 \\
(0.02)\end{array}$ \\
\hline $\begin{array}{l}\text { Perceived COVID-19 threat to life and health }(\text { severe }) \times \text { social } \\
\text { support }\end{array}$ & & & & $\begin{array}{l}0.14^{*} \\
(0.07)\end{array}$ & & & & $\begin{array}{c}0.02 \\
(0.02)\end{array}$ \\
\hline Adjusted $\mathrm{R}^{2}$ & 0.090 & 0.118 & 0.115 & 0.107 & 0.003 & 0.006 & 0.006 & 0.005 \\
\hline
\end{tabular}

SE Standard Error

${ }^{a}$ Reference group was people who perceived COVID-19 as not at all/slightly threatening to their life and health $\$$ Variables are mean centered

$+p<0.1 ; * p<.05 ; * * p<.01 ; * * * p<.001$

This effect only changed slightly across subsequent models. In model 2 , the family and social support variables were added and an association between social support and depression symptoms was observed $(\beta=-0.12$; $p<0.01)$.
The effect of an interaction between the perceived risk of COVID-19 infection and family support was examined on depression symptoms in model 3 , and loneliness in model 4. However, the interactions did not show any significant association. 
Table 4 The buffering role of psychosocial supports in the association between perceived risk of COVID-19 infection, depression symptoms and loneliness

\begin{tabular}{|c|c|c|c|c|c|c|c|c|}
\hline & \multicolumn{4}{|c|}{ Depression } & \multicolumn{4}{|c|}{ Loneliness } \\
\hline & $\begin{array}{l}\text { Model } 1 \\
\beta(\mathrm{SE})\end{array}$ & $\begin{array}{l}\text { Model } 2 \\
\beta(\mathrm{SE})\end{array}$ & $\begin{array}{l}\text { Model } 3 \\
\beta(\mathrm{SE})\end{array}$ & $\begin{array}{l}\text { Model } 4 \\
\beta \text { (SE) }\end{array}$ & $\begin{array}{l}\text { Model } \\
1 \\
\beta(\mathrm{SE})\end{array}$ & $\begin{array}{l}\text { Model } \\
2 \\
\beta(\mathrm{SE})\end{array}$ & $\begin{array}{l}\text { Model } \\
3 \\
\beta(\mathrm{SE})\end{array}$ & $\begin{array}{l}\text { Model } \\
4 \\
\beta(\mathrm{SE})\end{array}$ \\
\hline Age & $\begin{array}{l}-0.05 \\
(0.04)\end{array}$ & $\begin{array}{l}-0.04 \\
(0.04)\end{array}$ & $\begin{array}{l}-0.05 \\
(0.04)\end{array}$ & $\begin{array}{l}-0.05 \\
(0.04)\end{array}$ & $\begin{array}{l}-0.01 \\
(0.01)\end{array}$ & $\begin{array}{l}-0.01 \\
(0.01)\end{array}$ & $\begin{array}{l}-0.01 \\
(0.01)\end{array}$ & $\begin{array}{l}-0.01 \\
(0.01)\end{array}$ \\
\hline Gender $(1=$ female $)$ & $\begin{array}{l}0.76 \\
(0.44)\end{array}$ & $\begin{array}{l}0.86+ \\
(0.44)\end{array}$ & $\begin{array}{l}0.87 * \\
(0.44)\end{array}$ & $\begin{array}{l}0.87 * \\
(0.44)\end{array}$ & $\begin{array}{l}0.15 \\
(0.12)\end{array}$ & $\begin{array}{l}0.16 \\
(0.12)\end{array}$ & $\begin{array}{l}0.17 \\
(0.12)\end{array}$ & $\begin{array}{l}0.16 \\
(0.12)\end{array}$ \\
\hline Education ( 1 = college and above $)$ & $\begin{array}{l}-0.49 \\
(0.78)\end{array}$ & $\begin{array}{l}-0.59 \\
(0.78)\end{array}$ & $\begin{array}{l}-0.56 \\
(0.79)\end{array}$ & $\begin{array}{l}-0.60 \\
(0.78)\end{array}$ & $\begin{array}{l}-0.12 \\
(0.21)\end{array}$ & $\begin{array}{l}-0.14 \\
(0.22)\end{array}$ & $\begin{array}{l}-0.16 \\
(0.22)\end{array}$ & $\begin{array}{l}-0.15 \\
(0.22)\end{array}$ \\
\hline Marital status ( 1 =currently married) & $\begin{array}{l}-1.85^{* *} \\
(0.68)\end{array}$ & $\begin{array}{l}-2.07 * * * \\
(0.71)\end{array}$ & $\begin{array}{l}-2.05^{* *} \\
(0.71)\end{array}$ & $\begin{array}{l}-2.07 * * \\
(0.71)\end{array}$ & $\begin{array}{l}-0.17 \\
(0.18)\end{array}$ & $\begin{array}{l}-0.22 \\
(0.20)\end{array}$ & $\begin{array}{l}-0.23 \\
(0.20)\end{array}$ & $\begin{array}{l}-0.23 \\
(0.20)\end{array}$ \\
\hline Annual income (1 =“>=30,000 RMB") & $\begin{array}{l}-0.68 \\
(0.51)\end{array}$ & $\begin{array}{l}-0.66 \\
(0.51)\end{array}$ & $\begin{array}{l}-0.68 \\
(0.51)\end{array}$ & $\begin{array}{l}-0.67 \\
(0.51)\end{array}$ & $\begin{array}{l}-0.16 \\
(0.14)\end{array}$ & $\begin{array}{l}-0.16 \\
(0.14)\end{array}$ & $\begin{array}{l}-0.15 \\
(0.14)\end{array}$ & $\begin{array}{l}-0.15 \\
(0.14)\end{array}$ \\
\hline Self-rated health & $\begin{array}{l}-1.40 * * * \\
(0.30)\end{array}$ & $\begin{array}{l}-1.28 * * * \\
(0.30)\end{array}$ & $\begin{array}{l}-1.30 * * * \\
(0.31)\end{array}$ & $\begin{array}{l}-1.28 * * * \\
(0.31)\end{array}$ & $\begin{array}{l}-0.13 \\
(0.08)\end{array}$ & $\begin{array}{l}-0.11 \\
(0.09)\end{array}$ & $\begin{array}{l}-0.12 \\
(0.09)\end{array}$ & $\begin{array}{l}-0.11 \\
(0.09)\end{array}$ \\
\hline \multicolumn{9}{|l|}{ COVID-19 related stressor } \\
\hline \multicolumn{9}{|l|}{ Perceived risk of infection ${ }^{\text {a }}$} \\
\hline Fair & $\begin{array}{l}0.60 \\
(0.46)\end{array}$ & $\begin{array}{l}0.60 \\
(0.46)\end{array}$ & $\begin{array}{l}0.58 \\
(0.46)\end{array}$ & $\begin{array}{l}0.60 \\
(0.46)\end{array}$ & $\begin{array}{l}0.26^{*} \\
(0.12)\end{array}$ & $\begin{array}{l}0.26^{*} \\
(0.13)\end{array}$ & $\begin{array}{l}0.27 * \\
(0.13)\end{array}$ & $\begin{array}{l}0.26^{*} \\
(0.12)\end{array}$ \\
\hline Probably/definitely & $\begin{array}{l}2.32 * * * \\
(0.67)\end{array}$ & $\begin{array}{l}2.26^{* * *} \\
(0.67)\end{array}$ & $\begin{array}{l}2.16^{* * *} \\
(0.68)\end{array}$ & $\begin{array}{l}2.26^{* * *} \\
(0.67)\end{array}$ & $\begin{array}{l}0.57 * * \\
(0.18)\end{array}$ & $\begin{array}{l}0.56^{* * *} \\
(0.18)\end{array}$ & $\begin{array}{l}0.53 * * \\
(0.19)\end{array}$ & $\begin{array}{l}0.56^{* * * *} \\
(0.19)\end{array}$ \\
\hline \multicolumn{9}{|l|}{ Psychosocial resources } \\
\hline Family support & & $\begin{array}{l}0.10 \\
(0.07)\end{array}$ & $\begin{array}{l}0.10 \\
(0.09)\end{array}$ & $\begin{array}{l}0.10 \\
(0.07)\end{array}$ & & $\begin{array}{l}0.02 \\
(0.02)\end{array}$ & $\begin{array}{l}0.01 \\
(0.02)\end{array}$ & $\begin{array}{l}0.02 \\
(0.02)\end{array}$ \\
\hline Social support & & $\begin{array}{l}-0.12^{* *} \\
(0.04)\end{array}$ & $\begin{array}{l}-0.12^{* *} \\
(0.04)\end{array}$ & $\begin{array}{l}-0.12^{*} \\
(0.05)\end{array}$ & & $\begin{array}{l}-0.02+ \\
(0.01)\end{array}$ & $\begin{array}{l}-0.02+ \\
(0.01)\end{array}$ & $\begin{array}{l}-0.02 * \\
(0.01)\end{array}$ \\
\hline \multicolumn{9}{|l|}{ Interaction terms } \\
\hline Perceived risk of COVID-19 infection (fair) $\times$ family support & & & $\begin{array}{l}-0.03 \\
(0.10)\end{array}$ & & & & $\begin{array}{l}0.02 \\
(0.03)\end{array}$ & \\
\hline $\begin{array}{l}\text { Perceived risk of COVID-19 infection (probably/definitely) } \times \\
\text { family support }\end{array}$ & & & $\begin{array}{l}-0.10 \\
(0.15)\end{array}$ & & & & $\begin{array}{l}0.06 \\
(0.04)\end{array}$ & \\
\hline Perceived risk of COVID-19 infection (fair) $\times$ social support & & & & $\begin{array}{l}0.01 \\
(0.06)\end{array}$ & & & & $\begin{array}{l}0.01 \\
(0.02)\end{array}$ \\
\hline $\begin{array}{l}\text { Perceived risk of COVID-19 infection (probably/definitely) } \times \\
\text { social support }\end{array}$ & & & & $\begin{array}{l}0.03 \\
(0.08)\end{array}$ & & & & $\begin{array}{l}0.01 \\
(0.02)\end{array}$ \\
\hline Adjusted $\mathrm{R}^{2}$ & 0.105 & 0.120 & 0.121 & 0.121 & 0.030 & 0.021 & 0.039 & 0.036 \\
\hline
\end{tabular}

SE Standard Error

${ }^{a}$ Reference group was people who perceived that they are definitely not/probably not at risk of COVID-19 infection \$Variables are mean centered

$+p<0.1 ; * p<.05 ; * * p<.01 ; * * * p<.001$

\section{Discussion}

We utilized cross-sectional data collected online in midMarch 2020 from China, to investigate whether psychosocial support buffered how COVID-19 related stressors affected the mental health of individuals in China during the COVID-19 quarantine. This study had two important findings: 1) While perceived severity of COVID-19 was not associated with depression symptoms and loneliness, it was the perception of how threatening COVID-19 is to one's life and health, and the perceived risk of infection that mattered most for the mental health status during quarantine; and 2) the role of 
psychosocial support in buffering the impact of COVID-19 related stressor on mental health varied across outcome measures and perspective of COVID-19 stressor. To the best of our knowledge, the buffering effect of psychosocial support on COVID-19 related stressors has not been previously investigated. The study is relevant as it contributes to the emerging body of literature trying to understand how the COVID-19 impacts the mental health of individuals.

Findings from this study suggest that people's mental health was impacted by the outbreak of COVID-19, similar to the psychological burden caused by SARS of 2003 (Ko et al., 2006), H1N1 influenza of 2009 (Cowling et al., 2010), MERS of 2012 (Jeong et al., 2016), and complementing other studies that have associated COVID19 related stressors with poor mental health (GonzálezSanguino et al., 2020; Lin et al., 2020; Qi et al., 2020; Salari et al., 2020; Ye et al., 2020). However, our finding showed that it is the extent to which such contagion is considered to pose a risk to someone personally and not its general severity that affects one's mental health. This lends credence to the aspect of the stress process model, suggesting that events that elicit stress in individuals (life-strains) are likely to impact mental health. Events that may be tagged by such label borders on factors like desirability (Gersten et al., 1977; Vinokur \& Selzer, 1975), or the degree of control people have over them (Fairbank \& Hough, 1979). The COVID-19 being a deadly contagion, with no known therapeutic or vaccine (at least at that time), means that people had less control over it, and was obviously less desired. As a result, people who had the perception of being definitely/probably at risk of infection, or sees the contagion to be severely threatening to their life and health, were more at risk of depression symptoms and loneliness.

With regard to the buffering role of psychosocial support, first, a significant negative association was observed in the interaction between perceived severity of COVID-19 and psychosocial support. It suggested that both family and social support buffered the negative effect of the perceived severity of COVID-19 on loneliness, though the effect of social support was just marginal. This further shows the efficacy of psychosocial support in mitigating the effect of traumatic life events (Chen et al., 2014; Cohen \& Wills, 1985; Lakey \& Cohen, 2000; Pearlin et al., 1981; Xu, Ou, et al., 2020). Noting the events that surrounded the timing of the data collection as previously mentioned, family togetherness at that time could mitigate the feeling of loneliness arising from the quarantine (Shah et al., 2020). Having close relations with whom to physically and constantly interact while in quarantine could eliminate perceived loneliness. The marginal effect of social support could be explained by the fact that physical social interaction outside the confines of the household was mostly limited during the period. As a result, interactions with colleagues, friends, etc., may only be via the internet or phone, which may not have the same weight of significance when compared with face-to-face communication (Lewandowski et al., 2011).

Secondly, psychosocial support was seen not to effectively mitigate the negative effect of perception of a severe threat of COVID-19 on depression symptoms. A finding contrary to the buffering hypothesis (Cohen \& Wills, 1985). This result may be explained by the fact that when support providers are equally yoked by the same stress, as probably the case with COVID-19 (Shah et al., 2020), it may fail to provide tangible assistance or provide inappropriate or too little emotional support, thereby reducing or eliminating the effectiveness of the effort (Bolger et al., 1996). This finding is also similar to an anecdotal report on SARS (Maunder, 2009).

Thirdly, the result showed that psychosocial support was not a significant buffer in the relationship between the perception of being at risk of COVID-19 infection and mental health. The severity of infection rate in people's location (Kowal et al., 2020; Qian \& Li, 2020), or the frequency at which they or members of their household are exposed to people outside of the household could lead people to hold the perception of being at risk of COVID-19 infection (Xu, Liu, et al., 2020). A study had reported that family members of essential workers during the early stages of the national quarantine showed more depression symptoms (Ying et al., 2020), probably due to fear of household transmission if that person was infected. This shared-fear may weaken the "support element" in such psychosocial resources. Moreover, when people perceived that they were at risk of COVID-19 infection, faced with a shortage of medical resources and basic supplies, the effectiveness of family and social support also may be compromised by abnormally elevated feelings of hopelessness and desperation.

Furthermore, it is worthy of note, that the important element in any social relationship, useful for psychosocial support is emotional support (Thoits, 1985). It is quite possible individuals may obtain this from both, either or neither of the circles of family and social network groups. This may partly explain the reason for the mixed patterns concerning the buffering role of psychosocial support.

\section{The Implication for Policy and Practice}

Finding from this study offers some implications for practice and policy. Firstly, our study had shown that it is the personal perception of risk and not the general severity of COVID-19 that impacts mental health. Therefore, social workers and mental health professionals can devise a proper measure to target the most vulnerable groups, such as the general population who have been exposed to the risk of infection and the front-line healthcare workers. Secondly, and particularly in countries still witnessing a continued surge in cases of COVID-19, people in isolation or quarantine should be encouraged to use online video to maintain and strengthen 
communication with their close relations as a strategy for preserving good mental health during the course. Third, as it was observed that family and social support may sometimes not effectively buffer the negative impact of COVID-19 related stressors, there is a need for professional psychological services. According to the COVID-19 epidemic situation and local prevention and control measures, professional psychological counseling services should be provided at the community level or on the Internet. Special focus should also be on members of empty-nest families, as they are more likely to experience loneliness or depression (P. Cheng et al., 2015).

\section{Limitations}

Several limitations are associated with our data and study design. First, the cross-sectional nature of the data makes it impossible to draw a causal relationship. Second, data were collected by voluntary participation using an online medium. As a result, the data may be biased against people not having access to a computing device to complete the survey, and all population groups may not be adequately represented. Some caution should therefore be exercised when generalizing our findings to other populations. In this regard, future studies could consider devising a process to make data collection more representative of the general population. Thirdly, there is the possibility of endogeneity of omitted variables. Specifically, routine daily activities were greatly interrupted during the national quarantine, which could also influence the mental health of people at that time. Lastly, our study had only considered psychosocial support from two perspectives family and social support. However, psychosocial support could be further classified into emotional or instrumental supports. Further studies are needed to provide an insight as to how both differ from the perspective of the buffering hypothesis in the context of COVID-19 stressors.

Despite the above limitations, the strength of our study lies in the use of a tool with good validity and reliability to measure mental health. Also, the data used in this study were collected during the remission phase of the pandemic in China. Therefore, responses were more likely to reflect the construct for which the questions were designed, as opposed to if it had been collected in a retrospective context. Additionally, the sample of our study reflects a nationwide representation, therefore, to an extent, our findings may be generalizable for a national context.

\section{Conclusion}

Data from this study revealed mixed findings on the buffering impact of psychosocial resources on the relationship between COVID-19 related stressors and mental health among Chinese during the remission phase of the COVID-19 quarantine in
China. It is important for people under shelter-in-place order or quarantine during the outbreak of an infectious disease to maintain social relations as a strategy for the preservation of mental health, and also for professionals to look for avenues to render professional service for people who may be experiencing mental health issues in the period of physical social restrictions.

Permission to Reproduce Material from Other Sources No materials from other sources.

Authors' Contributions Ying Wang: Conceptualization, Methodology, Formal analysis, Investigation, Data curation. Tolulope Ariyo: WritingOriginal draft preparation. Huijun Liu: Supervision, Project administration. Chenjuan Ma: Conceptualization, Writing- Reviewing and Editing.

Funding The author(s) received no financial support for the research, authorship, and/or publication of this article.

Data Availability The datasets generated during and analyzed during the current study are available from the corresponding author on reasonable request.

\section{Declarations}

Ethics Approval The research protocol was reviewed and approved by the Biomedical Ethics Committee of Xi'an Jiaotong University.

Conflict of Interest The authors declare that they have no conflict of interest.

\section{References}

Ahmed, M. Z., Ahmed, O., Aibao, Z., Hanbin, S., Siyu, L., \& Ahmad, A. (2020). Epidemic of COVID-19 in China and associated psychological problems. Asian Journal of Psychiatry, 51, 102092.

Andresen, E. M., Malmgren, J. A., Carter, W. B., \& Patrick, D. L. (1994). Screening for depression in well older adults: Evaluation of a short form of the CES-D. American Journal of Preventive Medicine, 10(2), 77-84.

Bolger, N., Vinokur, A. D., Foster, M., \& Ng, R. (1996). Close relationships and adjustment to a life crisis: The case of breast cancer. Journal of Personality and Social Psychology, 70(2), 283-294. https://doi.org/10.1037/0022-3514.70.2.283.

Brooks, S. K., Webster, R. K., Smith, L. E., Woodland, L., Wessely, S., Greenberg, N., \& Rubin, G. J. (2020). The psychological impact of quarantine and how to reduce it: Rapid review of the evidence. The Lancet, 395(10227), 912-920. https://doi.org/10.1016/S01406736(20)30460-8.

Chen, Y., Hicks, A., \& While, A. E. (2014). Loneliness and social support of older people in China: A systematic literature review. Health \& Social Care in the Community, 22(2), 113-123. https://doi.org/10. 1111/hsc.12051.

Cheng, P., Jin, Y., Sun, H., Tang, Z., Zhang, C., Chen, Y., Zhang, Q., Zhang, Q., \& Huang, F. (2015). Disparities in prevalence and risk indicators of loneliness between rural empty nest and non-empty nest older adults in Chizhou, China. Geriatrics and Gerontology International, 15(3), 356-364. https://doi.org/10.1111/ggi.12277. 
Cheng, S. T., \& Chan, A. C. M. (2005). The Center for Epidemiologic Studies Depression Scale in older Chinese: Thresholds for long and short forms. International Journal of Geriatric Psychiatry, 20(5), 465-470. https://doi.org/10.1002/gps.1314.

Chou, R. J. A. (2011). Filial piety by contract? The emergence, implementation, and implications of the "family support agreement" in China. Gerontologist, 51(1), 3-16. https://doi.org/10.1093/geront/ gnq059.

Cohen, S., \& Wills, T. A. (1985). Stress, social support, and the buffering hypothesis. Psychological Bulletin, 98(2), 310-357. https://doi.org/ 10.1037/0033-2909.98.2.310.

Cowling, B. J., Ng, D. M. W., Ip, D. K. M., Liao, Q., Lam, W. W. T., Wu, J. T., Lau, J. T. F., Griffiths, S. M., \& Fielding, R. (2010). Community psychological and behavioral responses through the first wave of the 2009 influenza a(H1N1) pandemic in Hong Kong. Journal of Infectious Diseases, 202(6), 867-876. https://doi. org/10.1086/655811.

Dershem, L. D., Patsiorkovski, V. V., \& O’Brien, D. J. (1996). The use of the CES-D for measuring symptoms of depression in three rural Russian villages. Social Indicators Research, 39(1), 89-108. https://doi.org/10.1007/BF00300834.

Dong, X., Simon, M. A., Gorbien, M., Percak, J., \& Golden, R. (2007). Loneliness in older Chinese adults: A risk factor for elder mistreatment. Journal of the American Geriatrics Society, 55(11), 18311835. https://doi.org/10.1111/j.1532-5415.2007.01429.x.

Duan, H., Yan, L., Ding, X., Gan, Y., Kohn, N., \& Wu, J. (2020). Impact of the COVID-19 pandemic on mental health in the general Chinese population: Changes, predictors and psychosocial correlates. Psychiatry Research, 293(August), 113396. https://doi.org/10. 1016/j.psychres.2020.113396.

Fairbank, D. T., \& Hough, R. L. (1979). Life event classifications and the event-illness relationship. Journal of Human Stress, 5(3), 41-47.

Gersten, J. C., Langner, T. S., Eisenberg, J. G., \& Simcha-Fagan, O. (1977). An evaluation of the etiologic role of stressful life-change events in psychological disorders. Journal of Health and Social Behavior, 18, 228-244.

González-Sanguino, C., Ausín, B., Castellanos, M. Á., Saiz, J., LópezGómez, A., Ugidos, C., \& Muñoz, M. (2020). Mental health consequences during the initial stage of the 2020 coronavirus pandemic (COVID-19) in Spain. Brain, Behavior, and Immunity, 87, 172176. https://doi.org/10.1016/j.bbi.2020.05.040.

Holmes, E. A., O'Connor, R. C., Perry, V. H., Tracey, I., Wessely, S., Arseneault, L., Ballard, C., Christensen, H., Cohen Silver, R., Everall, I., Ford, T., John, A., Kabir, T., King, K., Madan, I., Michie, S., Przybylski, A. K., Shafran, R., Sweeney, A., et al. (2020). Multidisciplinary research priorities for the COVID-19 pandemic: A call for action for mental health science. The Lancet Psychiatry, 7(6), 547-560. https://doi.org/10.1016/S22150366(20)30168-1.

Huang, Y., \& Zhao, N. (2020). Generalized anxiety disorder, depressive symptoms and sleep quality during COVID-19 outbreak in China: A web-based cross-sectional survey. Psychiatry Research, 288, 112954. https://doi.org/10.1016/j.psychres.2020.112954.

Hughes, M. E., Waite, L. J., Hawkley, L. C., \& Cacioppo, J. T. (2004). A short scale for measuring loneliness in large surveys: Results from two population-based studies. Research on Aging, 26(6), 655-672. https://doi.org/10.1177/0164027504268574.

Jeong, H., Yim, H. W., Song, Y. J., Ki, M., Min, J. A., Cho, J., \& Chae, J. H. (2016). Mental health status of people isolated due to Middle East respiratory syndrome. Epidemiology and Health, 38, e2016048. https://doi.org/10.4178/epih.e2016048.

Johns Hopkins University and Medicine. (2020). Coronavirus Resource Center. https://coronavirus.jhu.edu/

Ko, C. H., Yen, C. F., Yen, J. Y., \& Yang, M. J. (2006). Psychosocial impact among the public of the severe acute respiratory syndrome epidemic in Taiwan. Psychiatry and Clinical Neurosciences, 60(4), 397-403. https://doi.org/10.1111/j.1440-1819.2006.01522.x.

Kowal, M., Coll-Martín, T., Ikizer, G., Rasmussen, J., Eichel, K., Studzińska, A., Koszałkowska, K., Karwowski, M., Najmussaqib, A., Pankowski, D., Lieberoth, A., \& Ahmed, O. (2020). Who is the most stressed during the COVID-19 pandemic? Data from 26 countries and areas. Applied Psychology. Health and Well-Being, 12(4), 946-966. https://doi.org/10.1111/aphw.12234.

Lakey, B., \& Cohen, S. (2000). Social support theory and measurement. In S. Cohen, L. G. Underwood, \& B. H. Gottlieb (Eds.), Social support measurement and intervention (pp. 29-52). Oxford University Press.

Lewandowski, J., Rosenberg, B. D., Jordan Parks, M., \& Siegel, J. T. (2011). The effect of informal social support: Face-to-face versus computer-mediated communication. Computers in Human Behavior, 27(5), 1806-1814. https://doi.org/10.1016/j.chb.2011. 03.008 .

Li, G., Hu, H., Dong, Z., \& Arao, T. (2013). Development of the Chinese family support scale in a sample of Chinese patients with hypertension. PLoS One, 8(12), 1-7. https://doi.org/10.1371/journal.pone. 0085682

Lin, Y., Hu, Z., Alias, H., \& Wong, L. P. (2020). Knowledge, attitudes, impact, and anxiety regarding COVID-19 infection among the public in China. Frontiers in Public Health, 8, 236. https://doi.org/10. 3389/fpubh.2020.00236.

Maunder, R. G. (2009). Was SARS a mental health catastrophe? General Hospital Psychiatry, 31(4), 316-317. https://doi.org/10.1016/j. genhosppsych.2009.04.004.

National Cancer Institute. (n.d.). Psychosocial support. Retrieved December 17, 2020, from https://www.cancer.gov/publications/ dictionaries/cancer-terms/def/psychosocial-support

Pandey, D., Bansal, S., Goyal, S., Garg, A., Sethi, N., Pothiyill, D. I., Sreelakshmi, E. S., Sayyad, M. G., \& Sethi, R. (2020). Psychological impact of mass quarantine on population during pandemics-The COVID-19 lock-down (COLD) study. PLoS One, 15(10), e0240501.

Pearlin, L. I., Lieberman, M. A., Menaghan, E. G., \& Mullan, J. T. (1981). The stress process. Journal of Health and Social Behavior, 22(4), 337-356. https://doi.org/10.2307/2136676.

Qi, M., Zhou, S. J., Guo, Z. C., Zhang, L. G., Min, H. J., Li, X. M., \& Chen, J. X. (2020). The effect of social support on mental health in Chinese adolescents during the outbreak of COVID-19. Journal of Adolescent Health, 67(4), 514-518. https://doi.org/10.1016/j. jadohealth.2020.07.001.

Qian, D., \& Li, O. (2020). The relationship between risk event involvement and risk perception during the COVID-19 outbreak in China. Applied Psychology. Health and Well-Being, 12(4), 983-999. https://doi.org/10.1111/aphw.12219.

Rogers, J. P., Chesney, E., Oliver, D., Pollak, T. A., McGuire, P., FusarPoli, P., Zandi, M. S., Lewis, G., \& David, A. S. (2020). Psychiatric and neuropsychiatric presentations associated with severe coronavirus infections: A systematic review and meta-analysis with comparison to the COVID-19 pandemic. The Lancet Psychiatry, 7(7), 611627. https://doi.org/10.1016/S2215-0366(20)30203-0.

Salari, N., Hosseinian-Far, A., Jalali, R., Vaisi-Raygani, A., Rasoulpoor, S., Mohammadi, M., Rasoulpoor, S., \& Khaledi-Paveh, B. (2020). Prevalence of stress, anxiety, depression among the general population during the COVID-19 pandemic: A systematic review and meta-analysis. Globalization and Health, 16(1), 1-11. https://doi.org/ 10.1186/s12992-020-00589-w.

Shah, S. G. S., Nogueras, D., van Woerden, H. C., \& Kiparoglou, V. (2020). The COVID-19 pandemic: A pandemic of lockdown loneliness and the role of digital technology. Journal of Medical Internet Research, 22(11), 1-7. https://doi.org/10.2196/22287.

Sharma, R. A., Maheshwari, S., \& Bronsther, R. (2020). COVID-19 in the era of loneliness. Current Psychiatry, 19(5), 31-33. 
Sweeny, K., Rankin, K., Cheng, X., Hou, L., Long, F., Meng, Y., Azer, L., Zhou, R., \& Zhang, W. (2020). Flow in the time of COVID-19: Findings from China. PLoS One, 15(11), 1-12. https://doi.org/10. 1371/journal.pone.0242043.

Thoits, P. A. (1985). Social support and psychological well-being: Theoretical possibilities. In B. L. Wilcox, E. M. Vernberg, I. G. Sarason, \& B. R. Sarason (Eds.), Social support (pp. 51-72). Springer.

Turner, R. J., \& Brown, R. L. (2010). Social support and mental health. In T. L. Scheid \& T. N. Brown (Eds.), A handbook for the study of mental health (2nd ed., pp. 202-206). Cambridge University Press.

Vinokur, A., \& Selzer, M. L. (1975). Desirable versus undesirable life events: Their relationship to stress and mental distress. Journal of Personality and Social Psychology, 32(2), 329-337.

World Health Organization. (2020a). Coronavirus disease (COVID-19) advice for the public. https://www.who.int/emergencies/diseases/ novel-coronavirus-2019/advice-for-public

World Health Organization. (2020b, January 12). Novel Coronavirus. https:/www.who.int/csr/don/12-january-2020-novel-coronaviruschina/en/

Xu, J., Ou, J., Luo, S., Wang, Z., Chang, E., Novak, C., Shen, J., Zheng, S., \& Wang, Y. (2020). Perceived social support protects lonely people against COVID-19 anxiety: A three-wave longitudinal study in China. Frontiers in Psychology, 11, 566965. https://doi.org/10. 3389/fpsyg.2020.566965.

Xu, X.-K., Liu, X. F., Wu, Y., Ali, S. T., Du, Z., Bosetti, P., Lau, E. H. Y., Cowling, B. J., \& Wang, L. (2020). Reconstruction of transmission pairs for novel coronavirus disease 2019 (COVID-19) in mainland China: Estimation of superspreading events, serial interval, and hazard of infection. Clinical Infectious Diseases, 71, 3163-3167. https://doi.org/10.1093/cid/ciaa790.

Ye, Z., Yang, X., Zeng, C., Wang, Y., Shen, Z., Li, X., \& Lin, D. (2020). Resilience, social support, and coping as mediators between COVID-19-related stressful experiences and acute stress disorder among college students in China. Applied Psychology. Health and Well-Being, 12(4), 1074-1094. https://doi.org/10.1111/aphw. 12211.

Ying, Y., Ruan, L., Kong, F., Zhu, B., Ji, Y., \& Lou, Z. (2020). Mental health status among family members of health care workers in Ningbo, China, during the coronavirus disease 2019 (COVID-19) outbreak: A cross-sectional study. BMC Psychiatry, 20, 379. https:// doi.org/10.1186/s12888-020-02784-w.

Publisher's Note Springer Nature remains neutral with regard to jurisdictional claims in published maps and institutional affiliations. 